Article

\title{
Osteogenesis and Antibacterial Activity of Graphene Oxide and Dexamethasone Coatings on Porous Polyetheretherketone via Polydopamine-Assisted Chemistry
}

\author{
Ling Ouyang ${ }^{1}$, Meiyao $\mathrm{Qi}^{1}$, Shengnan Wang ${ }^{1}$, Shan $\mathrm{Tu}^{1}{ }^{1}$, Bogang $\mathrm{Li}^{1}{ }^{1}$, Yi Deng ${ }^{2,3, *(1)}$ \\ and Weizhong Yang ${ }^{1, *}$ \\ 1 School of Materials Science and Engineering, Sichuan University, Chengdu 610065, China; \\ 2016223015073@stu.scu.edu.cn (L.O.); 2015181641016@stu.scu.edu.cn (M.Q.); \\ 2016223010037@stu.scu.edu.cn (S.W.); 15883670708@163.com (S.T.); luohongbo5989@sina.com (B.L.) \\ 2 School of Chemical Engineering, Sichuan University, Chengdu 610065, China \\ 3 Department of Mechanical Engineering, The University of Hong Kong, Pokfulam, Hong Kong 999077, China \\ * Correspondence: dengyibandeng@scu.edu.cn or dengyi@hku.hk (Y.D.); ywz@scu.edu.cn (W.Y.)
}

Received: 18 April 2018; Accepted: 24 May 2018; Published: 28 May 2018 updates

\begin{abstract}
Endowing implants with antibacterial ability and osteogenic ability plays important roles in preventing post-operative bacterial contamination and facilitating integration between implants and osseous tissue, consequently reducing implant failure rates. In this study, we develop a facile and versatile strategy with dopamine as an auxiliary for construction of dexamethasone (Dex)/liposome porous coatings. In detail, the surfaces of sulfonated polyetheretherketone (SP) plates are coated with polydopamine firstly and then modified with graphene oxide (GO) and dexamethasone (Dex)-loaded liposome, which is verified by contact angle, X-ray photoelectron spectroscopy (XPS), attenuated total reflection infrared (ATR), and Raman spectra. The results of our study suggest that the GO and Dex are successfully coated on the samples' surfaces. In vitro cell attachment, growth, differentiation, and apatite deposition tests all illustrate that the substrate coated with GO and Dex can significantly accelerate the proliferation and osteogenic differentiation of MC3T3 cells compared with the pristine sulfonated polyetheretherketone (PEEK). Additionally, it exhibits acceptable antibacterial activity against E. coli and S. aureus in vitro. Altogether, our results demonstrate that the modified GOand Dex-loaded substrates are endowed with impressive biocompatibility and certain antibacterial qualities, making it possible for future application as a perspective implant material.
\end{abstract}

Keywords: dexamethasone; liposome; graphene oxide; cytocompatibility; antibacterial

\section{Introduction}

Implantable biomaterials have been extensively used in clinical application when irreparable bone loss occurs resulting from diseases, accidents, military injuries, or aging [1]. Combined with the specific progenitor cell population, a scaffold supplied with differentiation factors (DF) can regulate the dimensional and temporal organization of the cell adhesion, growth, differentiation, and function as the osteogenic expression in tissue engineering [2,3]. Nevertheless, on account of bacteria colonization and toxin-release, it can be definitely deduced that the therapeutic implants and nearby tissue will suffer from disastrous post-operative complications, including, for instance, abnormal allergic and infectious reactions, consequently resulting in implant failure [4]. Thus, there is an urgent demand for a functional implant material whose surface is designed to possess both antibacterial and osteogenesis competences, for further enhancement of post-operative success rates. 
Metallic biomaterials, like titanium alloys, possess many valuable metallic advantages including contour machining, low melting point, as well as cytocompatibility, whereas there still exist some defects like potential metal ion release and improper elastic modulus between the metals and human bones [5]. Polyetheretherketone (PEEK) is a kind of desired substitution material and a class of semi-crystalline polymer materials which has high temperature resistance, chemical corrosion resistance and other physical and chemical properties [6]. Apart from the thermoplasticity, radiolucency, and good biocompatibility, its biomechanical properties, such as the elastic modulus, has been demonstrated to be similar to natural human bone which is much more excellent than metallic materials, which takes the advantage of effectively decreasing the stress shielding influence [6-12]. However, the inferior osteoinduction and bioinert properties of PEEK limit its application in clinical implants [13]. To address this concern, sulfonated treatment by concentrated sulfuric acid on PEEK surface produces a porous network structure on the PEEK sample. The 3D porous structure is profitable for cell attachment and proliferation in tissue engineering due to its ideal microenvironment structure which is similar to the extracellular matrix $[14,15]$. However, the defect still exists for SP, for example, its cytocompatibility is inferior because of the residual sulfuric acid. Consequently, lots of efforts including physical blending $[16,17]$ and surface modification [18-21] have offered effective ways to improve the surface physical and biological properties. Among these, surface coating is an effective and simple way to create a bioactive surface.

Graphene oxide (GO), as a single sheet of sp2-hybridized carbon atoms arranged within a honeycomb lattice, is one of the most promising nanostructures with unique physical, chemical, electrical, and mechanical properties, which qualifies it as a promising nanomaterial in bioengineering surface modification [22-24]. Besides, the GO basal plane has functional groups of phenol hydroxyl and epoxide with carboxylic groups at the margin $[25,26]$. Therefore, with respect to the plentiful surface oxygen functional groups, GO specimens are endowed with excellent hydrophilicity, which is beneficial for the cellular adhesive process and proliferation while also effectively boosting apatite formation $[27,28]$. Furthermore, it has been reported that GO as well as reduced graphene oxide (rGO) provide strong antibacterial activity, but their ability of promoting osteoblastic differentiation still remains to be improved $[29,30]$.

As a common drug carrier, liposomes are known for being nanosized, biodegradable, low-toxic, and less immune-activating [31]. Liposomes can regulate drug loading and release according to their membrane composition, which has been applied for many bioactive reagents [32,33]. By introducing polymer auxiliary substances, such as polyethylene glycol (PEG), into the formulation can sterically stabilize the structure of liposomes to a functional degree. Previous research [34] has shown that liposomes are capable of intracellular release of dexamethasone (Dex: an osteogenic differentiation factor, which can mitigate and prevent tissue response to inflammation), suggesting its consistent and affirmative effectivity in motivating the osteogenic differentiation process of specific cells. Moreover, in light of the local delivery and release of liposomes, a possible way of maintaining therapeutic drug level at the target site has been put forward, so as to largely minimize the total dose of drug required compared with the usual administration dose. Simultaneously, by averting excessive drug exposure, undesirable side effects can also be reduced to a great extent $[35,36]$.

Taking these points into consideration, we employ a facile strategy to prepare GO and Dex/liposome-modified SP surfaces through dip-coating. Dopamine is introduced as an assistance firstly, and then Dex/liposome is grafted onto the surface of SP substrates. The efficacy of the GO and Dex/liposome-coated surfaces on antibacterial ability and cytocompatibility are investigated in vitro. We believe that the GO and Dex/liposome-coated SP biomaterials with good antibacterial ability and excellent cytocompatibility can pave a new way to orthopedic and dental applications for bone tissue engineering. 


\section{Materials and Methods}

\subsection{Materials}

Medical graded PEEK (450G) with a density about $1.30 \mathrm{~g} / \mathrm{cm}^{3}$ was purchased from Victrex plc (Thornton Cleveleys, UK). Tris (hydroxymethyl) aminomethane (Tris-HCl), HEPES buffer solution (HBS), and L- $\alpha$-phosphatidylcholine (HSPC) were obtained from Solarbio science and technology. (Beijing, China). Dexamethasone hydrochloride (Dex) and 1,2-distearoyl-sn-glycero-3phosphoethanolamine- $N$-[amino(polyethylene glycol)-2000] (ammonium salt) in this study were of reagent grade purchased from Sigma-Aldrich (St. Louis, MO, USA). Cholesterol (Chol, AR, >95\%) was obtained from Shanghai Yuanye Bio-Technology Co. Ltd. (Shanghai, China). Graphene oxide (GO) powders were supplied by TanFeng Tech (Suzhou, China). Concentrated sulfuric acid $\left(\mathrm{H}_{2} \mathrm{SO}_{4}, 98 \%\right)$, chloroform, acetone, and ethanol were obtained from KeLong chemical (Chengdu, China).

\subsection{Preparation of the Sulfonated PEEK (SP)}

For diverse experiments and tests, medical grade PEEK was machined to dimensions $\varphi 8.5 \times 2 \mathrm{~mm}$ for surface characterization, antibacterial tests, immersion tests, and in vitro studies on 48-well culture plate. Prior to the sulfonate treatment, the PEEK was washed in acetone, ethanol, and distilled water sequentially with ultrasonic agitation. Sulfonation treatment was carried out in supersonically stirred sulfuric acid (98\%) at room temperature for $5 \mathrm{~min}$ to obtain a uniform porous structure. The samples were subsequently taken out and immersed in acetone, ethanol, and distilled water with supersonic stirring for $10 \mathrm{~min}$ to remove the residues on the surface. This was performed 3 times and then the specimens were dried in an oven at $60^{\circ} \mathrm{C}$.

\subsection{Preparation of the Dex/Liposome}

Table 1 shows the liposome formulations used in this study. Liposome and Dex were first mixed in a round-bottomed flask with the appropriate amounts of each lipid and soaking with chloroform. The solvent chloroform was gradually evaporated using rotary evaporators. The obtained dry film was dispersed using vortex agitation with HBS. The multilamellar liposomal suspension was produced and kept in $4^{\circ} \mathrm{C}$ for later using.

Table 1. Liposome formulations (values expressed as a molar ratio).

\begin{tabular}{cccc}
\hline Dex & HSPC & Chol & DSPE-PEG-NH \\
\hline 0.2 & 2 & 0.1 & 0.1 \\
\hline
\end{tabular}

\subsection{Preparation of GO- and Liposome-Modified Surface}

GO slurry was prepared by dispersing $20 \mathrm{mg}$ GO in $40 \mathrm{~mL}$ distilled water with ultrasonic vibration for $4 \mathrm{~h}$ to form a uniform GO-water suspension. Then, the sulfonated samples were soaked in the GO-water solution for $10 \mathrm{~min}$ after immersion procedure, and the obtained GO-SP samples were dried at $100{ }^{\circ} \mathrm{C}$ for $10 \mathrm{~min}$. The aforementioned procedure was repeated five times to assure that the surfaces of the SP were completely coated with GO. The samples were finally disposed overnight at $100{ }^{\circ} \mathrm{C}$ and called GO-SP. SP and GO-SP were immersed in dopamine for $24 \mathrm{~h}$ and then $300 \mu \mathrm{L}$ Dex/liposome solution was added to get LIPO-SP and LIPO-GO-SP.

\subsection{Surface Characterization}

Field-emission scanning electron microscopy (FE-SEM, JSM-7500F, JEOL, Tokyo, Japan) was employed to observe the surface morphology of the prepared samples. All the specimens were coated with gold for $90 \mathrm{~s}$ before characterizations. Static water contact angle was used to test the surface hydrophilic properties of specimens and was evaluated by testing the sessile drop method 
on a drop-shape analysis system (JC2000C1, Shanghai ZhongChen digital technic, Shanghai, China) at ambient temperature and humidity. A $2 \mu \mathrm{L}$ deionized water droplet was dropped onto the specimen surface, and then the pictures were taken by a camera after stabilization. Atomic force microscopy (AFM, Multimode8, Bruker, Germany) was utilized in tapping modes in dry conditions at room temperature to investigate the changes of surface morphology. X-ray photoelectron spectroscopy (XPS, Thermo Fisher Scientific, Waltham, MA, USA) with a monochromatic Al K $\alpha$ radiation source at $300 \mathrm{~W}$ was used to detect the chemical constituents and elemental states of the samples for both survey and high-resolution spectra. Attenuated total reflection infrared (ATR, Nicolet 6700, Thermo Electron Corporation, Waltham, MA, USA) was employed to identify the functional groups of the samples with a spectral range from 4000 to $400 \mathrm{~cm}^{-1}$. Raman (LabRAM HR, HORIBA Jobin Yvon, Paris, France) spectra were determined to detect the existence of graphene oxide. Three duplicate samples of each group were examined.

\subsection{Cell Culture and Proliferation}

MC3T3 cells were cultivated in Dulbecco's modified eagle's medium (DEME, KGM12800-500, KeyGEN BioTECH, Nanjing, China), supplemented with $10 \%$ calf serum in a humidified incubator with $5 \% \mathrm{CO}_{2}$ at $37{ }^{\circ} \mathrm{C}$. Before cell culturing, the SP and GO-SP specimens were sterilized in an autoclave. LIPO-SP and LIPO-GO-SP specimens were sterilized with 75\% alcohol for $2 \mathrm{~h}$. The cultivation medium was refreshed every 2 days.

Moreover, proliferation of MC3T3 cells was assessed using the cell counting kit-8 assay (CCK-8). After cell counting, cells were seeded on the sample substrates at a density of $2 \times 10^{4}$ cells per well in 48-well plate (Nest Biotechnology, Wuxi, China). After incubating for 1, 3, and 5 days, $300 \mu \mathrm{L}$ of CCK-8 solution was added into each well for $2 \mathrm{~h}$ incubation. The absorbance value of the supernatant optical density (OD value) was measured at $450 \mathrm{~nm}$ with a microplate reader (SN680T1608203, BAIIU, Shanghai, China).

\subsection{Assessment of Cell Morphology}

To understand the effects of GO-SP on the growth of cells, confocal laser scanning microscopy (CLSM, A1R MP+, Nikon, Japan) was employed to detect the cytoskeleton and the nuclei of the MC3T3. The cells were fixed using $4 \%(v / v)$ paraformaldehyde in PBS buffer at room temperature for $30 \mathrm{~min}$. The samples were permeabilized with $0.1 \%(v / v)$ Triton X-100 (Solarbio, Beijing, China) for 5 min after being incubated for 2 days at an initial density of $2 \times 10^{4}$ cells per well. Cell cytoskeletons were stained with $200 \mu \mathrm{g} / \mathrm{mL}$ FITC-phalloidin (410D011, Solarbio, Beijing, China) for $30 \mathrm{~min}$. Cell nuclei were stained with $50 \mathrm{\mu g} / \mathrm{mL}$ 4',6-diamino-2-diamidino-2-phenylindole (DAPI) for $5 \mathrm{~min}$ at room temperature. All staining steps were washes in PBS buffer for 3 times. Cells were visualized immediately by confocal laser scanning microscopy.

\subsection{Formation of Bone-Like Apatite}

To evaluate the ability of apatite mineralization on SP and modified SP, the specimens with diameters of $8.5 \mathrm{~mm}$ were immersed in $1 \mathrm{~mL}$ simulated body fluid (SBF $\mathrm{pH}=7.4$ nearly equal to human blood plasma) at $37^{\circ} \mathrm{C}$ in a shaking incubator. The SBF solution was refreshed every day. After 7 and 12 days, the samples were collected from the solution and dried in ambient temperature. Finally, after mineralization, the components and micromorphology of the specimens were obtained by SEM equipped with energy dispersive spectrometer (EDS).

\subsection{Antibacterial Tests}

To assess the antibacterial ability of the samples, we seed the E. coli (ATCC 25922) and S. aureus (ATCC 25923) in the surface of samples. The SP and GO-SP were sterilized in an autoclave, while the liposome-loaded SP was sterilized in alcohol for $4 \mathrm{~h}$. Then, $400 \mu \mathrm{L}$ of solution containing $10^{6} \mathrm{CFU} / \mathrm{mL}$ of the bacterial was dropped on the samples in 48-well plates. Subsequently the plates 
were incubated at $37^{\circ} \mathrm{C}$ for $24 \mathrm{~h}$ and then the samples were taken out, gently rinsed with PBS twice, and the specimens were fixed with $2.5 \%$ glutaraldehyde for $4 \mathrm{~h}$. Then the samples were dehydrated with gradient ethanol solution (volume concentration $=35 \%, 50 \%, 75 \%, 90 \%, 95 \%, 100 \%$ ) for $10 \mathrm{~min}$ at each step. Finally, the observation of bacteria on their surfaces was observed by SEM after the dehydrated products were dried in air.

\subsection{Statistical Analysis}

All the quantitative data were expressed as mean \pm standard deviation. Statistical analysis was done using SPSS 10.0 software (IBM, Chicago, IL, USA). One-way analysis of variance (ANOVA) or Student's $t$-test was used to determine the significant differences among the groups, and $p$-values less than 0.05 were considered statistically significant.

\section{Result and Discussion}

\subsection{Result Description}

\subsubsection{Development and Characterization of the Samples}

Figure 1 depicts the formation of the GO and Dex/liposome-loaded surfaces, which have considerable antibacterial activities as well as good cytocompatibility. Dopamine molecules are capable of commencing self-polymerization and create a polydopamine (pDA) structure in weak alkaline conditions [37], which can form rich catechol moieties. When GO-SP samples immerse into the dopamine solution, the groups on GO surface, such as phenol hydroxyl, epoxide groups, and carboxylic groups, bind with the catechol moieties and form strong linkages. GO possesses numerous $\pi$-conjugated structures in the graphitic basal plan [38], which can form strong $\pi-\pi$ stacking interactions with the $\pi$-conjugated system (such as benzene rings) in SP and dopamine. Later, through formation of amine-catechol structures, Dex/liposomes were successfully introduced onto the pDA layer. The 1,2-distearoyl-sn-glycero-3-phosphoethanolamine-N-amino (poly(ethylene glycol))-2000 (ammonium salt) (DSPE-PEG-NH ${ }_{2}$ ) lipid, an ingredient of the liposome's outer layer, facilitates the bonding force onto the oxidized catechol groups, which are grafted on the pDA-SP decorated surface. Specifically, the $\mathrm{NH}_{2}$ groups react with oxidized catechol through chemical reaction, generating a stable and irreversible link [39].

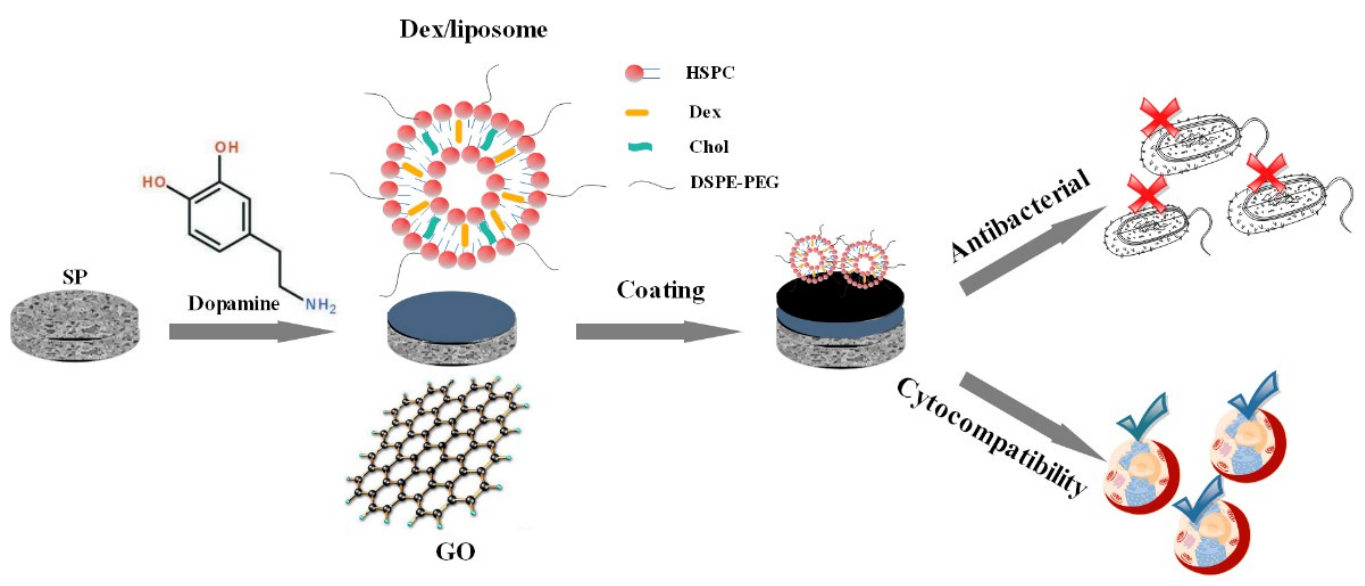

Figure 1. Schematic illustration for the formation of bioactive LIPO-GO-SP and its bioapplication.

The surface morphologies of the pristine SP, GO-decorated SP, and Dex-loaded liposomes immobilized at the surface of SP were detected by FE-SEM. Figure 2a shows the typical 3D porous structure, which is the characteristic structure after sulfonated treatment. The bright spots at high magnification may be attributed to the products of the sulfonation process. A uniform graphene oxide film 
covers the SP substrate, as shown in Figure 2d. Furthermore, the surface roughness of the GO-modified specimens decreases with addition of graphene oxide. After immersion in dopamine solution, many pDA particles (as the red arrow point) are observed on the pDA-GO-SP and LIPO-GO-SP groups. The pDA image can also be clearly observed at high magnification in Figure 2e. The high-magnification images of LIPO-SP and LIPO-GO-SP may present the existence of liposomes in the yellow squares.
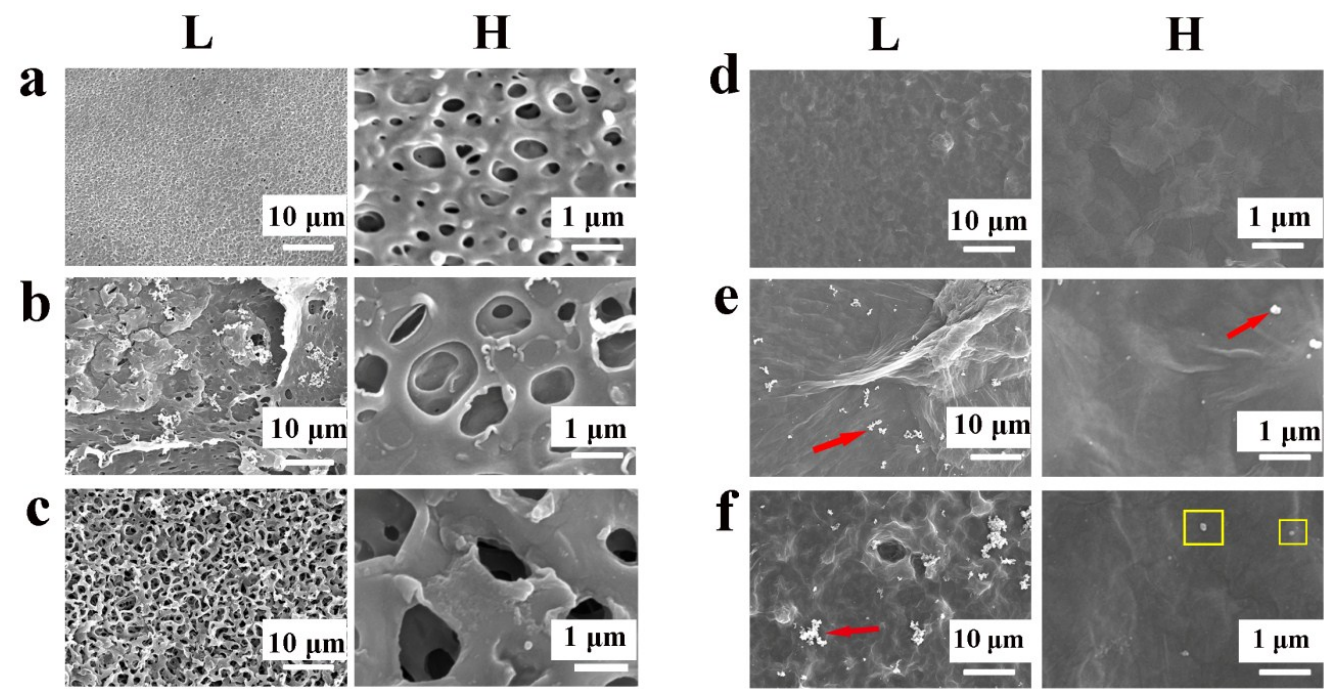

Figure 2. Surface morphology at low $(\mathrm{L})$ and high $(\mathrm{H})$ magnification of SP (a); pDA-SP (b); LIPO-SP (c); GO-SP (d); pDA-GO-SP (e); and LIPO-GO-SP (f). The red arrows point to $\mathrm{pDA}$ and the yellow squares may be liposome.

Figure 3a compares the roughness and structure investigated via AFM in contact mode before and after treatment. The roughness of the samples increases significantly after being coated with dopamine and liposomes. Besides, credited to the existence of Dex/liposomes, LIPO-SP has a relatively ragged surface, and becomes smooth after the introduction of GO. As a way of evaluating the samples' wettability, the contact angle (CA) was extensively investigated. As shown in Figure 3b, the CA of the GO-decorated surface decreased from $103.9^{\circ}$ to $57.1^{\circ}$. The hydrophilic property increased after coating the Dex/liposomes on the surface of the SP substrate, as the CA decrease to $40.4^{\circ}$, suggesting that pDA has already been loaded on the SP surfaces [40].
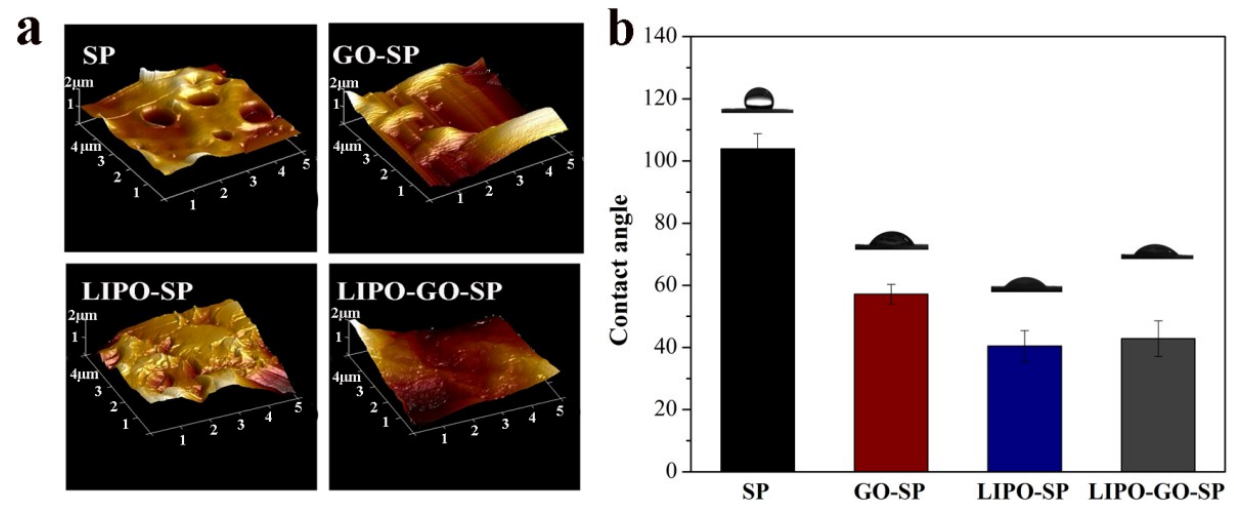

Figure 3. Typical AFM images of SP, GO-SP, LIPO-SP, and LIPO-GO-SP groups (a); the LIPO-GO-SP group is smoother than the LIPO-SP group after introducing GO. Static water contact angles of different samples (b).

Figure 4a shows the ATR spectra acquired from the SP control, GO-SP, LIPO-SP, and LIPO-GO-SP. The peaks at 1490 and $926 \mathrm{~cm}^{-1}$ are attributed to the diphenylketone bands for SP groups. The $\mathrm{C}-\mathrm{O}-\mathrm{C}$ 
stretching vibration of diaryl groups are observed at 1188 and $1158 \mathrm{~cm}^{-1}$, and a peak at $1600 \mathrm{~cm}^{-1}$ is related to $C=C$ in the benzene ring [41]. Some characteristic polymer bands, such as $O=S=O$ dissymmetric stretching at $1255 \mathrm{~cm}^{-1}$ and $\mathrm{S}=\mathrm{O}$ symmetric stretching at $1050 \mathrm{~cm}^{-1}$, are detected on the SP groups due to the sulfonation. For the samples modified with GO, two peaks at $1725 \mathrm{~cm}^{-1}$ are attributed to slight carbonyl $(\mathrm{C}=\mathrm{O})$ stretching vibrations. The peak at $1119 \mathrm{~cm}^{-1}$ is assigned to the $\mathrm{C}-\mathrm{O}-\mathrm{C}$ stretching vibration. As for the samples of LIPO-SP and LIPO-GO-SP, two characteristic absorption bands at 1050 and $1099 \mathrm{~cm}^{-1}$ are assigned to asymmetric $\mathrm{P}-\mathrm{O}$ stretching. It clearly indicates that liposomes are immobilized successfully on the pDA-coated surfaces. In the Raman spectrum of Figure $4 \mathrm{~b}$, the $\mathrm{D}$ band (associated with the edge distortion and structural defects) and the $\mathrm{G}$ band (revealing the sp2 carbon structure) are the characteristic absorption bands [42]. The spectra of GO-SP have two associated bands: the $G$ band at $1595 \mathrm{~cm}^{-1}$ and the D band at $1326 \mathrm{~cm}^{-1}$. LIPO-GO-SP has two associated bands: the $G$ band at $1598 \mathrm{~cm}^{-1}$ and the $D$ band at $1347 \mathrm{~cm}^{-1}$, indicating the existence of GO. XPS was applied to assess the successful coating of liposomes on pDA-coated surfaces after grafting. Figure $4 \mathrm{c}$ shows the XPS spectra of the samples. The main components of the SP and GO-SP surfaces are C 1s, N 1s, and O 1s, and a few $S 2 p$ can be detected on the SP surface. The $C 1 s$ characteristic peaks of XPS corresponding with $\mathrm{C}=\mathrm{C}, \mathrm{C}-\mathrm{O}$, and $\mathrm{COOH}$ are distinct for LIPO-GO-SP sample which may contribute to the improved hydrophilicity on the sample surface. After grafting of liposomes onto the pDA-coated surfaces, the peak of a phosphorus signal (P 2s and P 2p) indicates successful coating of the liposomes, which is associated with the result of $\mathrm{P} 2 \mathrm{p}$ spectra (Figure $4 \mathrm{~d}$ ).
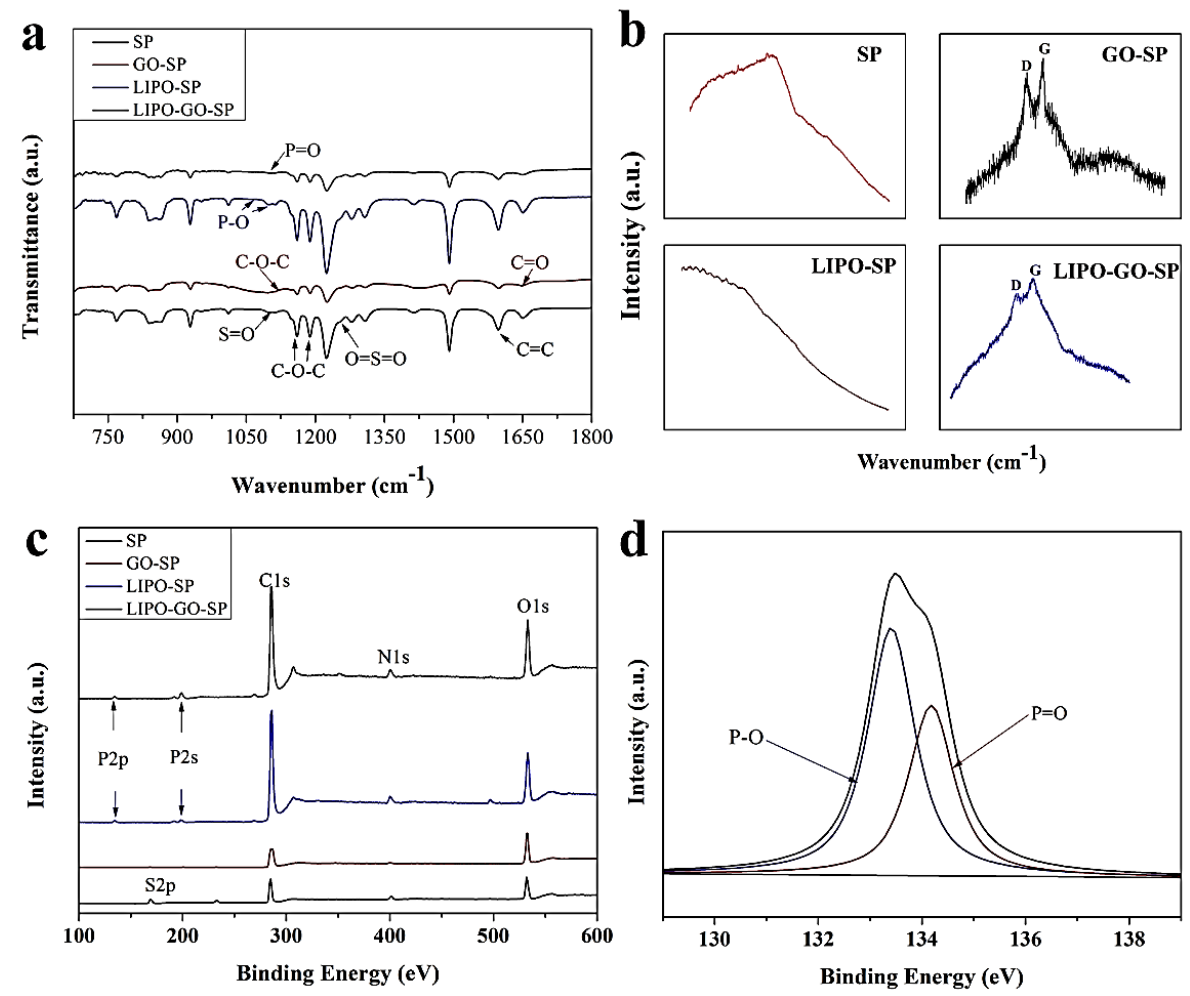

Figure 4. ATR-FTIR spectra (a) and Raman spectra (b) of different specimens; XPS full spectra (c) and XPS high-resolution spectra of P 2p (d) for SP, GO-SP, LIPO-SP, and LIPO-GO-SP.

From all the above surface characterization tests, the conclusion can be safely drawn that GO and Dex/liposomes are successfully introduced onto the surface of SP. Moreover, as far as the results of XPS are concerned, the phosphorus is indispensable in the composition of the liposomes [39]. The phosphorus peak shows up after the introduction of Dex/liposomes, verifying successful liposome grafting. 


\subsubsection{Cytocompatibility}

The cytocompatibility of the GO and Dex/liposome-coated surfaces for MC3T3 cell is an indispensable element that should be assessed. Figure 5 shows the MC3T3 cell viability by CCK-8, which can be directly revealed by the OD value measured at $450 \mathrm{~nm}$. Cell viabilities of SP and LIPO-SP keep almost constantly low from the 1st day to the 3rd day, then slightly increase from the 3rd day to the 5th day. Meanwhile, among the five-day period, cells on the surface of GO-SP and LIPO-GO-SP samples are of much higher vitality with a stable growing speed, which surpass that of the unmodified group. The OD values increase as time goes on, suggesting that the GO and Dex/liposome-coated surfaces have excellent cytocompatibility and promote proliferation of MC3T3 cells. Hence, it can be concluded that the addition of GO promotes cell proliferation and increases the cytocompatibility of our modified materials.

Typically, cells in contact with biomaterials will undergo morphological changes to stabilize the interface between the cell and the material [43]. In order to further detect the proliferation and morphology of MC3T3 cells, the cells were seeded on the samples at an initial density of $2 \times 10^{4}$ cells per well, and observations through SEM were done at the 1st and 3rd culturing days. Figure 6 shows the image of MC3T3 cells attached on the samples' surfaces. At the first day, cells are spherical on the GO-SP group, and filipodium can be observed, while the cells on SP and LIPO-SP exhibit fusiformis shape (as the yellow arrow point). However, as time increases to 3 days, the MC3T3 cells attach and spread on the surfaces of all the samples. The proliferation of MC3T3 cells was investigated by F-actin and DAPI staining under a confocal laser scanning microscope (Figure 7). Accordingly, the cell nucleus and the cyto-filaments are stained by DAPI and phalloidin, which respectively appear to be fluorescent blue and red under CLSM. After a two-day culture, cells grew well on all surfaces, especially on the group of GO-modified specimens, suggesting high cell viability. Cells reach their confluence and entered the differentiation process on GO-SP and LIPO-GO-SP samples.

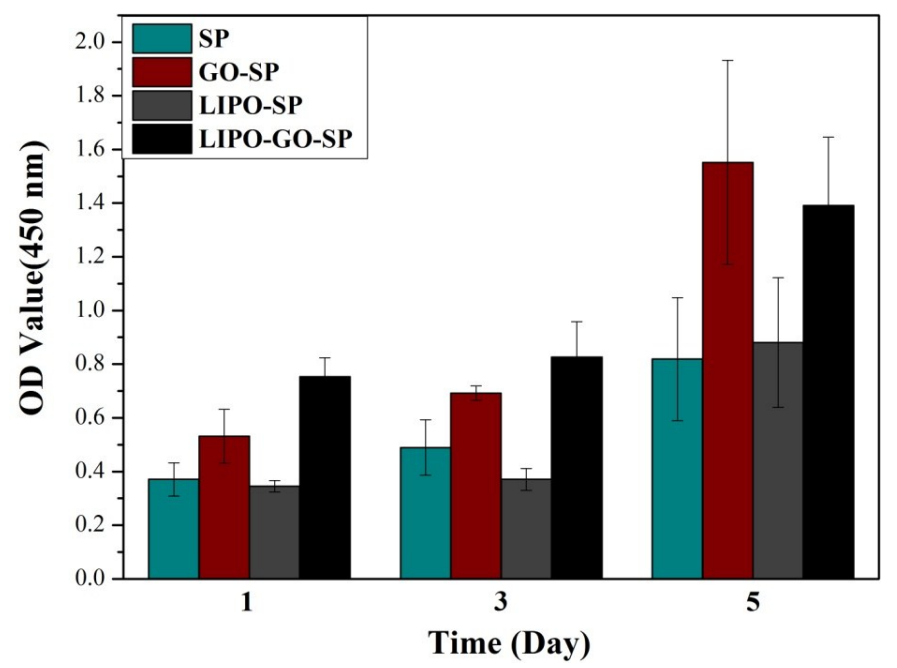

Figure 5. Cell viability and proliferation after culturing for 1, 3, and 5 days determined by CCK-8 kit. 


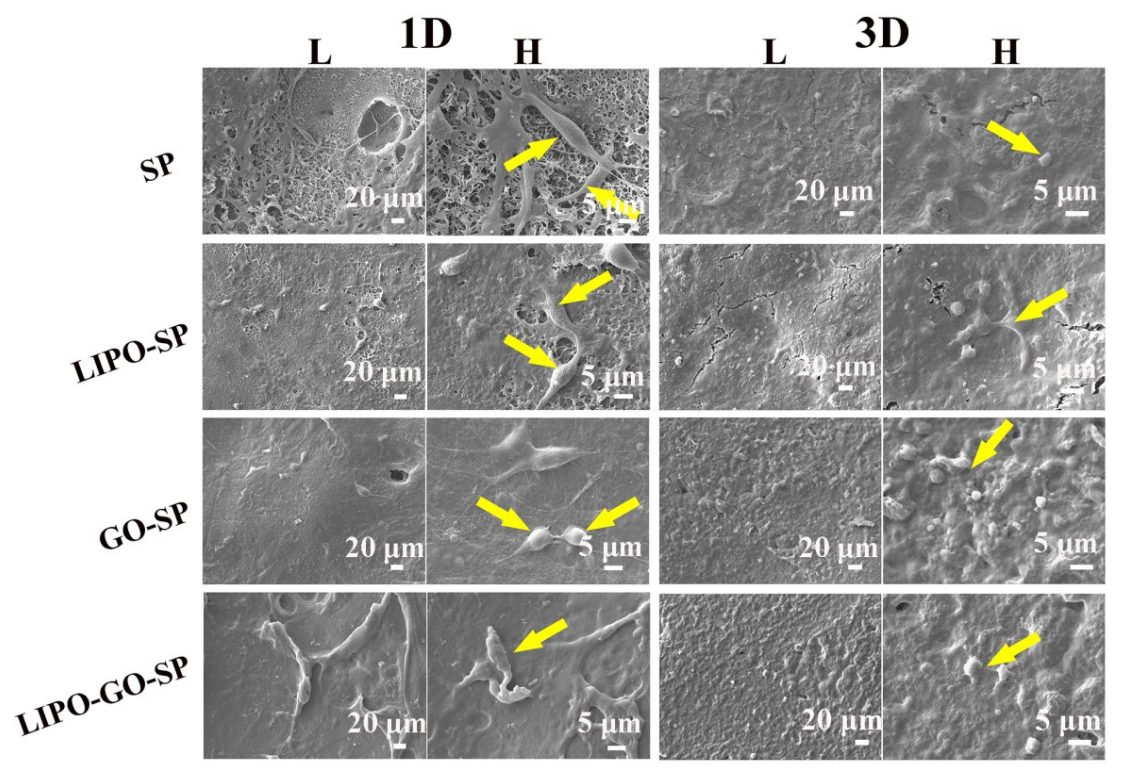

Figure 6. SEM images showing the morphologies of MC3T3 cells adhering to the specimens after incubation for 1 (1D) and 3 days (3D). The $\mathrm{L}$ and $\mathrm{H}$ represent the corresponding cell morphologies at low and high magnification, respectively. The yellow arrows point MC3T3 cells.

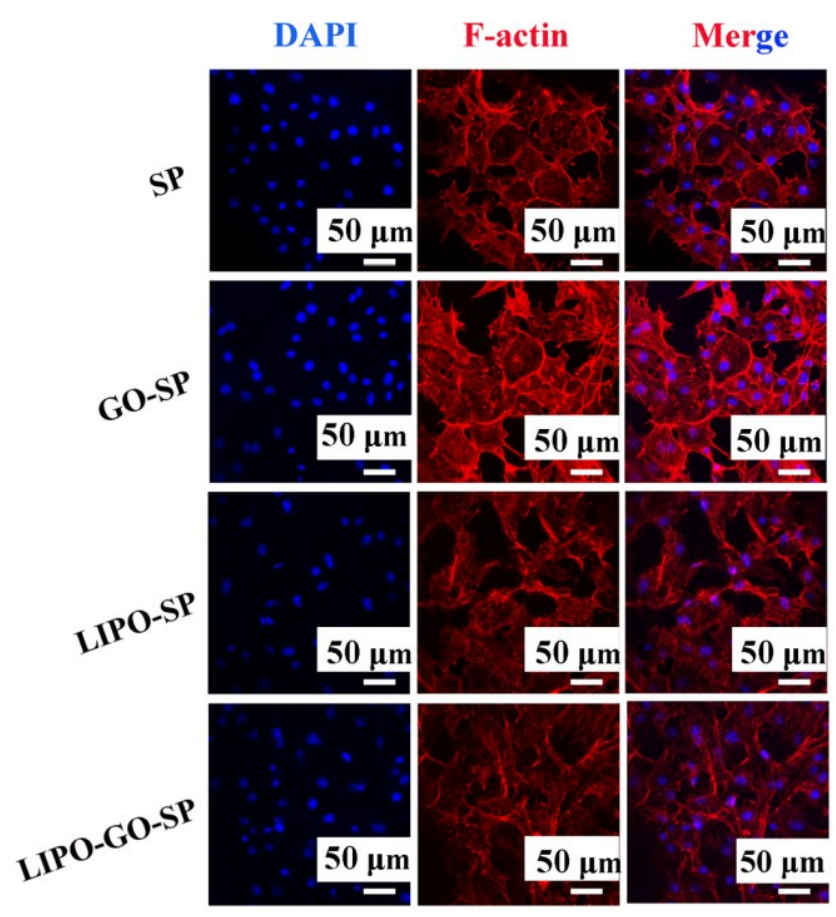

Figure 7. Confocal laser scanning microscopy images of MC3T3 cells after phalloidin and DAPI staining on specimens for 2 days. The nuclei are stained blue, and the plasmodesmata are stained red.

The apatite-formation ability when soaking the samples in SBF solution with ionic concentrations similar to those of human blood is an important representation of the in vitro bone-bonding ability [44]. Figure 8 shows the SEM images of the surface morphology of the SP, GO-SP, LIPO-SP, and LIPO-GO-SP samples. It is obvious that rounded nodules are observed on all samples surface after 7 and 12 days of soaking. Besides, they all form many more particles after 12 days than after 7 days. Furthermore, the GO-SO and LIPO-GO-SP surfaces are almost fully covered with spherical particles. 
7D

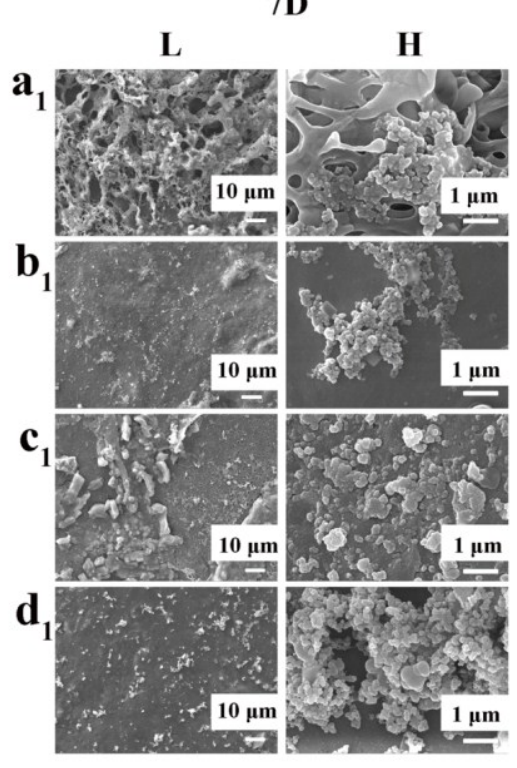

12D

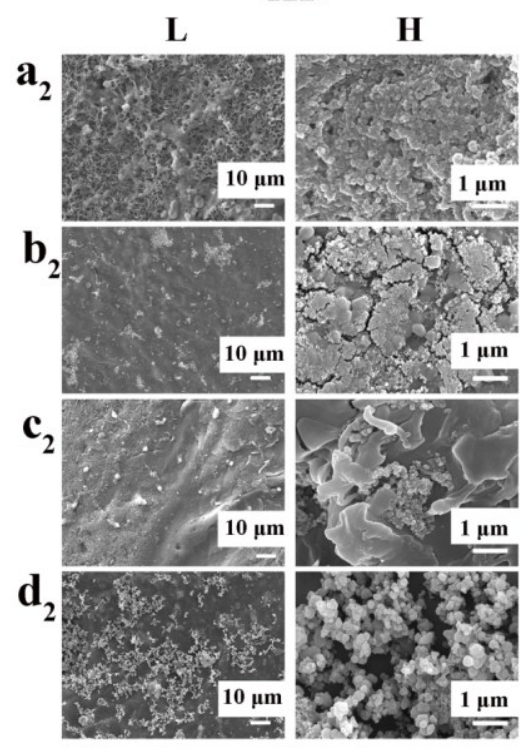

Figure 8. SEM images of the samples after soaking in simulated body fluids for 7 (7D) and 12 days (12D) at low (L) and high (H) magnifications, respectively. SP $\left(\mathbf{a}_{1}, \mathbf{a}_{2}\right)$; GO-SP $\left(\mathbf{b}_{1}, \mathbf{b}_{2}\right)$; LIPO-SP $\left(\mathbf{c}_{1}, \mathbf{c}_{2}\right)$; LIPO-GO-SP $\left(\mathbf{d}_{\mathbf{1}}, \mathbf{d}_{\mathbf{2}}\right)$.

Our results demonstrate that surfaces co-loaded with GO and Dex/liposomes may facilitate MC3T3 cell adhesion and spreading on the substrates. Apart from this, it is widely acknowledged that the existence of lamellipodia and filopodia is a symbol of mature cell spreading [39], which can be easily observed on GO-SP and LIPO-GO-SP samples (Figure 6). MC3T3 cells cultured on the GO and Dex/liposome-coated groups exhibited more adherent filopodia and spread more cyto-filaments, compared with cells in the SP and LIPO-SP groups, indicating that GO and Dex/liposomes have a stimulatory role on the growth of MC3T3 cells. Surfaces coated with GO and Dex/liposomes can endow the substrates with more satisfactory cytocompatibility. CLSM results also show the excellent cell proliferation and even differentiation trend on our multi-modified specimens. Besides, massive studies [45-47] have demonstrated that the hydrophilicity of materials plays a crucial role in cell attachment and adherence. The hydrophilic groups on GO and liposome edges, such as $\mathrm{OH}^{-}$and $\mathrm{COO}^{-}$, may absorb proteins through electrostatic interactions [48] which can control cell adhesion and stimulate characteristic gene expression. Analyzing the results of cell viability (CCK-8), combined with water contact angle testing, the viability of MC3T3 cells on GO-SP and LIPO-GO-SP surfaces exceed the others to a large degree, indicating that co-modification with GO and Dex/liposome improves cell attachment, which has a positive correlation with surface hydrophilicity according to large amount of previous research [46]. The synergistic effects between GO and Dex/liposome play a vital effect in cytocompatibility.

\subsubsection{Antibacterial Activity}

As is shown in Figure 9, the antibacterial ability varies among the surfaces of SP, GO-SP, LIPO-SP, and LIPO-GO-SP samples when cultivating E. coli and S. aureus bacteria for $24 \mathrm{~h}$. According to Figure $9 \mathrm{a}_{1}$, E. coli grow vigorously on the surface of the bare SP, where their distinctive holonomic-rod character can be observed. After modification with GO (Figure $9 b_{1}$ ), the typical morphological features of E. coli transform into a crushed and fragmentized shape (red arrow) as the bacteria experience irreversible destruction, which is revealed under high magnification. Moreover, the introduction of Dex/liposomes also improves the anti-E. coli competence of the samples, which can be concluded by comparing Figure $9 \mathrm{a}_{1}, \mathrm{c}_{1}$. The total number of $E$. coli cells decreases after introducing Dex/liposomes. 
With the synergetic efforts of GO and Dex/liposomes, LIPO-GO-SP exhibits good anti-E. coli activity as bacteria cells distort and fracture (red arrow). On the other hand, with respect to anti-S. aureus ability, as shown in Figure $9 \mathrm{a}_{2}$, S. aureus covers nearly the entire surface of the bare SP due to the lack of an effective bactericidal substance. In Figure $9 b_{2}, d_{2}$, a sharp decrease in S. aureus count (yellow arrow) verifies that GO modification moderately improves the antibacterial competence of the surface.

E. coli

L

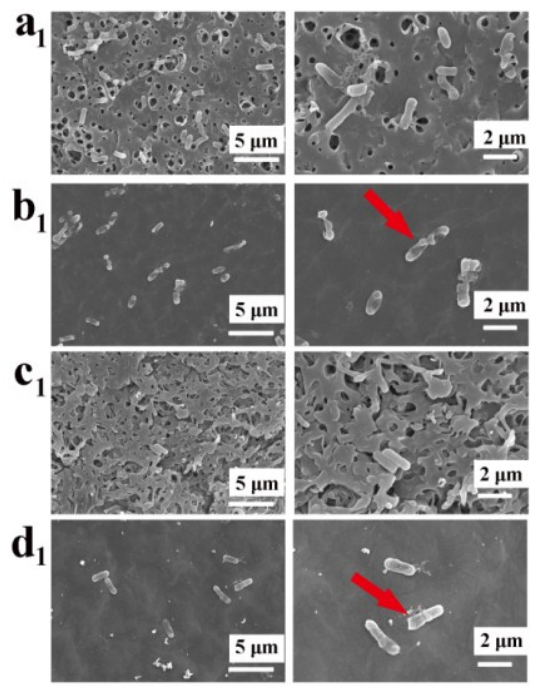

S. aureus

L $\quad$ H

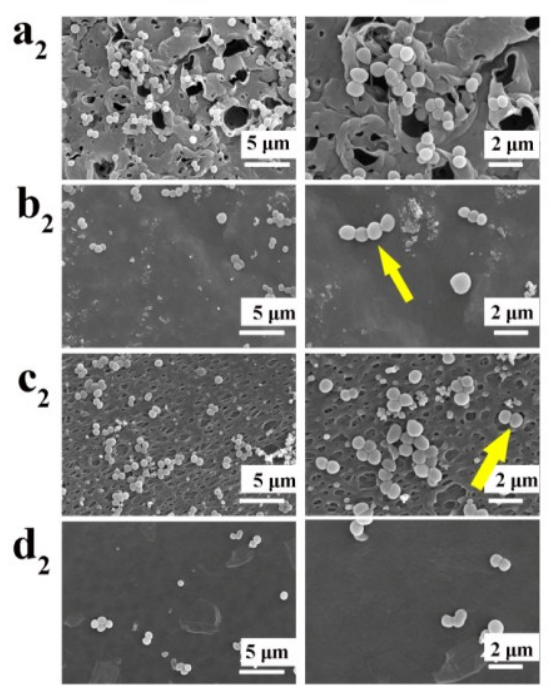

Figure 9. SEM images of bacteria on the different substrates cultured for $24 \mathrm{~h}$. SP $\left(\mathbf{a}_{1}, \mathbf{a}_{2}\right)$; GO-SP $\left(\mathbf{b}_{1}, \mathbf{b}_{2}\right)$; LIPO-SP $\left(\mathbf{c}_{1}, \mathbf{c}_{2}\right)$; LIPO-GO-SP $\left(\mathbf{d}_{\mathbf{1}}, \mathbf{d}_{\mathbf{2}}\right)$. The red arrow and yellow arrow show the morphologies of E. coli and $S$. aureus under high magnification, respectively.

In this study, strong suppression of E. coli growth and weaker suppression of $S$. aureus growth have been observed simultaneously. Hu's research [29] suggests that due to apparent morphological differences of E. coli (holonomic rod shape of $\sim 1 \mu \mathrm{m}$ in lateral diameter) and S. aureus (spherical shape of $\sim 0.5 \mu \mathrm{m}$ in diameter), the majority of $E$. coli cells tend to be flat on GO-modified surfaces, which leads to irreversible cell fragmentation and cell death, while small spherical S. aureus cells have a lower chance of making contact with the GO surface and therefore have a higher survival rate. In fact, keen-edged marginal parts of GO impose membrane stress on bacteria which contributes to cell destruction. Besides, GO produces oxidative stress that originates from reactive oxygen species (ROS) which harm bacterial DNA and structure, and are key to its anti-bacterial activity [49].

\section{Conclusion}

Overall, the functional surfaces modified with GO and Dex/liposomes on bioinert SP implants possess improved antibacterial activity and osteogenic ability. The hydrophilicity is improved after being coated with GO and Dex/liposomes. Raman spectra indicate that the GO is successfully covered on the substrates. Besides, X-ray photoelectron spectroscopy confirms that the Dex/liposomes are grafted onto the pDA-coated surfaces as expected. The cytocompatibility of the GO and Dex co-modified samples was enhanced according to the assessments of cell adhesion and proliferation. Furthermore, cells grown on the LIPO-GO-SP biocomposite exhibited more calcium deposition than those on pristine SP in SBF, which shows a potentially better osteogenic differentiation ability. After $24 \mathrm{~h}$ incubation, GO-SP and GO-LIPO-SP groups were found to possess good antibacterial activity against E. coli. Because of the acceptable antibacterial activity and excellent biocompatibility of GO and Dex dual-modified SP, it may provide prospects for prolonging the success rates of implantable materials. 
Author Contributions: L.O. and Y.D. conceived and designed the experiments. L.O., M.Q., S.W. and S.T. performed the experiments and analyzed the data. B.L. and W.Y. checked and revised the article. All authors contributed to the interpretation of the results and to the writing of the articles.

Funding: The work is financially support by Sichuan Science and Technology Program (2017FZ0046, 2018JZ0026), China Postdoctoral Science foundation (2017M610600), the Fundamental Research Funds for the Central Universities (Full-time Postdoctoral Research Funding of SCU, 2017SCU12016), and Hong Kong Scholars Program.

Acknowledgments: We would like to thank Chenghui Li and Hui Wang (Analytical \& Testing Center, SCU) for her help in CLSM and SEM observations, respectively. We also thank Daibing Luo (Analytical \& Testing Center, SCU) for his help in analysis.

Conflicts of Interest: The authors declare no competing financial interest.

\section{References}

1. Gentleman, E.; Swain, R.J.; Evans, N.D.; Boonrungsiman, S.; Jell, G.; Ball, M.D.; Shean, T.A.V.; Oyen, M.L.; Porter, A.; Stevens, M.M. Comparative materials differences revealed in engineered bone as a function of cell-specific differentiation. Nat. Mater. 2009, 8, 763-770. [CrossRef] [PubMed]

2. Hutmacher, D.W.; Schantz, J.T.; Lam, C.X.; Tan, K.C.; Lim, T.C. State of the art and future directions of scaffold-based bone engineering from a biomaterials perspective. J. Tissue Eng. Regen. Med. 2007, 1, 245-260. [CrossRef] [PubMed]

3. Martins, A.; Duarte, A.R.; Faria, S.; Marques, A.P.; Reis, R.L.; Neves, N.M. Osteogenic induction of hbmscs by electrospun scaffolds with dexamethasone release functionality. Biomaterials 2010, 31, 5875-5885. [CrossRef] [PubMed]

4. Wang, L.; He, S.; Wu, X.; Liang, S.; Mu, Z.; Wei, J.; Deng, F.; Deng, Y.; Wei, S. Polyetheretherketone/nanofluorohydroxyapatite composite with antimicrobial activity and osseointegration properties. Biomaterials 2014, 35, 6758-6775. [CrossRef] [PubMed]

5. Liu, X.; Chu, P.K.; Ding, C. Surface modification of titanium, titanium alloys, and related materials for biomedical applications. Mater. Sci. Eng. R. 2004, 47, 49-121. [CrossRef]

6. Kurtz, S.M.; Devine, J.N. Peek biomaterials in trauma, orthopedic, and spinal implants. Biomaterials 2007, 28, 4845-4869. [CrossRef] [PubMed]

7. Sagomonyants, K.; Jarman-Smith, M.L.; Devine, J.N.; Aronow, M.S.; Gronowicz, G.A. The in vitro response of human osteoblasts to polyetheretherketone (peek) substrates compared to commercially pure titanium. Biomaterials 2008, 29, 1563-1572. [CrossRef] [PubMed]

8. Williams, D. The role of nitric oxide in biocompatibility. Med. Device Technol. 2008, 19, 8-10. [PubMed]

9. Toth, J.M.; Wang, M.; Estes, B.T.; Scifert, J.L.; Rd, S.H.; Turner, A.S. Polyetheretherketone as a biomaterial for spinal applications. Biomaterials 2006, 27, 324-334. [CrossRef] [PubMed]

10. Xing, P.; Robertson, G.P.; Guiver, M.D.; Mikhailenko, S.D.; Wang, K.; Kaliaguine, S. Synthesis and characterization of sulfonated poly(ether ether ketone) for proton exchange membranes. J. Membr. Sci. 2004, 229, 95-106. [CrossRef]

11. Sobieraj, M.C.; Kurtz, S.M.; Rimnac, C.M. Notch sensitivity of peek in monotonic tension. Biomaterials 2009, 30, 6485-6494. [CrossRef] [PubMed]

12. Han, C.M.; Lee, E.J.; Kim, H.E.; Koh, Y.H.; Kim, K.N.; Ha, Y.; Kuh, S.U. The electron beam deposition of titanium on polyetheretherketone (peek) and the resulting enhanced biological properties. Biomaterials 2010, 31, 3465-3470. [CrossRef] [PubMed]

13. Ouyang, L.; Zhao, Y.; Jin, G.; Lu, T.; Li, J.; Qiao, Y.; Ning, C.; Zhang, X.; Chu, P.K.; Liu, X. Influence of sulfur content on bone formation and antibacterial ability of sulfonated peek. Biomaterials 2016, 83, 115-126. [CrossRef] [PubMed]

14. Nardecchia, S.; Serrano, M.C.; Gutiérrez, M.C.; Portolés, M.T.; Ferrer, M.L.; Monte, F.D. Osteoconductive performance of carbon nanotube scaffolds homogeneously mineralized by flow-through electrodeposition. Adv. Funct. Mater. 2012, 22, 4411-4420. [CrossRef]

15. Song, F.; Jie, W.; Zhang, T.; Li, W.; Jiang, Y.; Wan, L.; Liu, W.; Li, X.; Liu, B. Room-temperature fabrication of a three-dimensional reduced-graphene oxide/polypyrrole/hydroxyapatite composite scaffold for bone tissue engineering. RSC Adv. 2016, 6, 92804-92812. [CrossRef]

16. Amabile, G.; Meissner, A. Induced pluripotent stem cells: Current progress and potential for regenerative medicine. Trends Mol. Med. 2009, 15, 59-68. [CrossRef] [PubMed] 
17. Brunner, E.W.; Jurewicz, I.; Heister, E.; Fahimi, A.; Bo, C.; Sear, R.P.; Donovan, P.J.; Dalton, A.B. Growth and proliferation of human embryonic stem cells on fully synthetic scaffolds based on carbon nanotubes. ACS Appl. Mater. Interfaces 2014, 6, 2598-2603. [CrossRef] [PubMed]

18. Wang, S.; Deng, Y.; Yang, L.; Shi, X.; Yang, W.; Chen, Z.G. Enhanced antibacterial property and osteo-differentiation activity on plasma treated porous polyetheretherketone with hierarchical micro/nano-topography. J. Biomater. Sci. Polym. Ed. 2018, 5, 520-542. [CrossRef] [PubMed]

19. Xu, A.; Zhou, L.; Deng, Y.; Chen, X.; Xiong, X.; Deng, F.; Wei, S. A carboxymethyl chitosan and peptide-decorated polyetheretherketone ternary biocomposite with enhanced antibacterial activity and osseointegration as orthopedic/dental implants. J. Mater. Chem. B 2016, 4, 1878-1890. [CrossRef]

20. Xu, A.; Liu, X.; Gao, X.; Deng, F.; Deng, Y.; Wei, S. Enhancement of osteogenesis on micro/nano-topographical carbon fiber-reinforced polyetheretherketone-nanohydroxyapatite biocomposite. Mater. Sci. Eng. C Mater. 2015, 48, 592-598. [CrossRef] [PubMed]

21. Tao, L.; Jin, W.; Shi, Q.; Cao, H.; Ning, C.; Pan, X.; Jiang, X.; Liu, X.; Chu, P.K. Enhanced osteointegration on tantalum-implanted polyetheretherketone surface with bone-like elastic modulus. Biomaterials 2015, 51, $173-183$.

22. Zhang, Y.; Tan, Y.W.; Stormer, H.L.; Kim, P. Experimental observation of the quantum hall effect and berry's phase in graphene. Nature 2005, 438, 201-204. [CrossRef] [PubMed]

23. Katsnelson, M.I.; Novoselov, K.S. Graphene: New bridge between condensed matter physics and quantum electrodynamics. Solid State Commun. 2007, 143, 3-13. [CrossRef]

24. Novoselov, K.S.; Geim, A.K.; Morozov, S.V.; Jiang, D.; Katsnelson, M.I.; Grigorieva, I.V.; Dubonos, S.V.; Firsov, A.A. Two-dimensional gas of massless dirac fermions in graphene. Nature 2005, 438, $197-200$. [CrossRef] [PubMed]

25. Wang, Y.; Liu, Q.; Qi, Q.; Ding, J.; Gao, X.; Zhang, Y.; Sun, Y. Electrocatalytic oxidation and detection of $\mathrm{N}$-acetylcysteine based on magnetite/reduced graphene oxide composite-modified glassy carbon electrode. Electrochim. Acta 2013, 111, 31-40. [CrossRef]

26. Compton, O.C.; Nguyen, S.T. Graphene oxide, highly reduced graphene oxide, and graphene: Versatile building blocks for carbon-based materials. Small 2010, 6, 711-723. [CrossRef] [PubMed]

27. Wang, J.; Gao, X.; Wang, J.; Wei, Y.; Li, Z.; Gao, C. O-(carboxymethyl)-chitosan nanofiltration membrane surface functionalized with graphene oxide nanosheets for enhanced desalting properties. ACS Appl. Mater. Interfaces 2015, 7, 4381-4389. [CrossRef] [PubMed]

28. Ren, H.; Kulkarni, D.D.; Kodiyath, R.; Xu, W.; Choi, I.; Tsukruk, V.V. Competitive adsorption of dopamine and rhodamine 6G on the surface of graphene oxide. ACS Appl. Mater. Interfaces 2014, 6, 2459-2470. [CrossRef] [PubMed]

29. Hu, W.; Peng, C.; Luo, W.; Lv, M.; Li, X.; Li, D.; Huang, Q.; Fan, C. Graphene-based antibacterial paper. ACS Nano 2010, 4, 4317-4323. [CrossRef] [PubMed]

30. Akhavan, O.; Ghaderi, E. Toxicity of graphene and graphene oxide nanowalls against bacteria. ACS Nano 1936, 4, 5731-5736. [CrossRef] [PubMed]

31. Hallajnezhadi, S.; Hassan, M. Nanoliposome-based antibacterial drug delivery. Drug Deliv. 2013, 22, 581-589. [CrossRef] [PubMed]

32. Ju, R.J.; Li, X.T.; Shi, J.F.; Li, X.Y.; Sun, M.G.; Zeng, F.; Zhou, J.; Liu, L.; Zhang, C.X.; Zhao, W.Y. Liposomes, modified with PTD(HIV-1) peptide, containing epirubicin and celecoxib, to target vasculogenic mimicry channels in invasive breast cancer. Biomaterials 2014, 35, 7610-7621. [CrossRef] [PubMed]

33. Liu, Y.; Lu, W.L.; Guo, J.; Du, J.; Li, T.; Wu, J.W.; Wang, G.L.; Wang, J.C.; Zhang, X.; Zhang, Q. A potential target associated with both cancer and cancer stem cells: A combination therapy for eradication of breast cancer using vinorelbine stealthy liposomes plus parthenolide stealthy liposomes. J. Control. Release 2008, 129, 18-25. [CrossRef] [PubMed]

34. Oliveira, J.M.; Kotobuki, N.; Tadokoro, M.; Hirose, M.; Mano, J.F.; Reis, R.L.; Ohgushi, H. Ex vivo culturing of stromal cells with dexamethasone-loaded carboxymethylchitosan/poly(amidoamine) dendrimer nanoparticles promotes ectopic bone formation. Bone 2010, 46, 1424-1435. [CrossRef] [PubMed]

35. Kulkarni, M.; Greiser, U.; O’Brien, T.; Pandit, A. Liposomal gene delivery mediated by tissue-engineered scaffolds. Trends Biotechnol. 2010, 28, 28-36. [CrossRef] [PubMed]

36. Deng, Y.; Wei, S.; Yang, L.; Yang, W.; Dargusch, M.S.; Chen, Z.G. A novel hydrogel surface grafted with dual functional peptides for sustaining long-term self-renewal of human induced pluripotent stem cells and manipulating their osteoblastic maturation. Adv. Funct. Mater. 2018, 28, 1705546. [CrossRef] 
37. Lee, H.; Dellatore, S.M.; Miller, W.M.; Messersmith, P.B. Mussel-inspired surface chemistry for multifunctional coatings. Science 2007, 318, 426-430. [CrossRef] [PubMed]

38. Peng, S.; Pei, F.; Ping, W.; Wei, H.; Yang, Y.; Wang, G.; Gao, C.; Shuai, C. Graphene oxide as an interface phase between polyetheretherketone and hydroxyapatite for tissue engineering scaffolds. Sci. Rep. 2017, 7, 46604. [CrossRef] [PubMed]

39. Xu, X.; Wang, L.; Luo, Z.; Ni, Y.; Sun, H.; Gao, X.; Li, Y.; Zhang, S.; Li, Y.; Wei, S. Facile and versatile strategy for construction of anti-inflammatory and antibacterial surfaces with polydopamine-mediated liposomes releasing dexamethasone and minocycline for potential implants applications. ACS Appl. Mater. Interfaces 2017, 9, 43300-43314. [CrossRef] [PubMed]

40. Song, Y.; Ye, G.; Wu, F.; Wang, Z.; Liu, S.; Kopeć, M.; Wang, Z.; Chen, J.; Wang, J.; Matyjaszewski, K. Bioinspired polydopamine (PDA) chemistry meets ordered mesoporous carbons (OMCs): A benign surface modification strategy for versatile functionalization. Chem. Mater. 2016, 28, 5013-5021. [CrossRef]

41. Zhao, Y.; Wong, H.M.; Wang, W.; Li, P.; Xu, Z.; Chong, E.Y.; Yan, C.H.; Yeung, K.W.; Chu, P.K. Cytocompatibility, osseointegration, and bioactivity of three-dimensional porous and nanostructured network on polyetheretherketone. Biomaterials 2013, 34, 9264-9277. [CrossRef] [PubMed]

42. Yang, S.; Zhu, C.; Wang, G.; Mo, R.; He, P.; Sun, J.; Di, Z.; Kang, Z.; Yuan, N.; Ding, J. A new mild, clean and high-efficient method for preparation of graphene quantum dots without by-products. J. Mater. Chem. B 2015, 3, 6871-6876.

43. Sun, Y.; Deng, Y.; Ye, Z.; Liang, S.; Tang, Z.; Wei, S. Peptide decorated nano-hydroxyapatite with enhanced bioactivity and osteogenic differentiation via polydopamine coating. Colloids Surf. B Biointerfaces 2013, 111, 107-116. [CrossRef] [PubMed]

44. Kokubo, T.; Takadama, H. How useful is SBF in predicting in vivo bone bioactivity. Biomaterials 2006, 27, $2907-2915$. [CrossRef] [PubMed]

45. Park, J.W.; Kim, Y.J.; Jang, J.H.; Suh, J.Y. Surface characteristics and primary bone marrow stromal cell response of a nanostructured strontium-containing oxide layer produced on a microrough titanium surface. J. Biomed. Mater. Res. A 2012, 100, 1477-1487. [CrossRef] [PubMed]

46. Eriksson, C.; Nygren, H.; Ohlson, K. Implantation of hydrophilic and hydrophobic titanium discs in rat tibia: Cellular reactions on the surfaces during the first 3 weeks in bone. Biomaterials 2004, 25, 4759-4766. [CrossRef] [PubMed]

47. Zhao, L.; Liu, L.; Wu, Z.; Zhang, Y.; Chu, P.K. Effects of micropitted/nanotubular titania topographies on bone mesenchymal stem cell osteogenic differentiation. Biomaterials 2012, 33, 2629-2641. [CrossRef] [PubMed]

48. Ma, H.; Jiang, C.; Zhai, D.; Luo, Y.; Chen, Y.; Lv, F.; Yi, Z.; Deng, Y.; Wang, J.; Chang, J. A bifunctional biomaterial with photothermal effect fortumor therapy and bone regeneration. Adv. Funct. Mater. 2016, 26, 1197-1208. [CrossRef]

49. Gurunathan, S.; Han, J.W.; Dayem, A.A.; Eppakayala, V.; Kim, J.H. Oxidative stress-mediated antibacterial activity of graphene oxide and reduced graphene oxide in pseudomonas aeruginosa. Int. J. Nanomed. 2012, 7, 5901-5914. [CrossRef] [PubMed]

(C) 2018 by the authors. Licensee MDPI, Basel, Switzerland. This article is an open access article distributed under the terms and conditions of the Creative Commons Attribution (CC BY) license (http://creativecommons.org/licenses/by/4.0/). 